\title{
Morphology and Immunoprofiling of Benign Lymphoid Aggregates in Bone Marrow Biopsies of Lymphoma Patients
}

\author{
Alok Goel $^{2}$ Shivani Jain ${ }^{2}$ Rakesh Kapoor ${ }^{3}$

\footnotetext{
${ }^{1}$ Department of Pathology, Homi Bhabha Cancer Hospital and Research Centre, (A Unit of Tata Memorial Centre), Sangrur, Punjab, India

2Department of Medical Oncology, Homi Bhabha Cancer Hospital and Research Centre, (A Unit of Tata Memorial Centre), Sangrur, Punjab, India

${ }^{3}$ Department of Radiotherapy, Homi Bhabha Cancer Hospital and Research Centre, (A Unit of Tata Memorial Centre), Sangrur, Punjab, India
}

Supreet Kaur Kalra ${ }^{1}$ Sankalp Sancheti ${ }^{1}$ Puneet Kaur Somal ${ }^{1} \quad$ Akash Pramod Sali $^{1}$

\section{South Asian J Cancer 2021;10:265-266.}

The evaluation of bone marrow status is a key process in the initial workup of patients diagnosed with lymphoma as it is the most common site of extranodal involvement in lymphoid malignancies and plays an important role in staging and predicting prognosis in patients with lymphomas. We studied 121 cases of non-Hodgkin lymphoma (NHL) and Hodgkin lymphoma over a period of 3 years to gauge the incidence and pattern of marrow involvement. The highest incidence of bone marrow involvement at our center was seen in lymphoplasmacytic lymphoma followed by small lymphocytic lymphoma/chronic lymphocytic leukemia (SLL/CLL), mantle cell lymphoma, and marginal zone lymphoma astounding the fact that low grade lymphomas have a higher incidence of marrow involvement. The least common incidence of marrow involvement was seen in diffuse large B cell lymphomas (DLBCLs).

An interesting observation during the reevaluation of these cases was presence of benign lymphoid aggregates (BLA) in bone marrow biopsy (BMB) specimens, which when present, their distinction from NHL, particularly B cell lymphomas, can represent a diagnostic challenge.

We encountered five cases with BLA including one SLL/CLL, one follicular lymphoma, and three cases of DLBCL. Awareness about their morphological and immunohistochemical characteristics is extremely important to avoid overstaging and overtreatment in lymphoma cases.
However, BLA have not been studied or described extensively in literature and hence it is a potential pitfall.

BLA in bone marrow have been reported to be frequently associated with certain conditions including aging, autoimmune diseases, inflammatory conditions, and infectious disorders. ${ }^{1}$ They have also been reported to be commonly identified in patients with myeloproliferative neoplasms, especially primary myelofibrosis. Moreover, an increased incidence of BLA in patients with lymphoma who have been treated with rituximab has been reported. These aggregates are often found in postchemotherapy bone marrow specimens and can mimic residual lymphoma.

BLA require diligent distinction from lymphoma involvement in bone marrow biopsies. Criteria have been suggested in a limited number of studies to aid in this distinction.

Morphological and immunohistochemical differences between BLA and malignant lymphoid aggregates in bone marrow biopsies are presented in - Table 1.,3

According to Johnston et $\mathrm{al}^{1}{ }^{1}$ the identification of more than two of the listed five characteristics is strongly suggestive of malignancy and was statistically associated with malignant diagnoses in their study. Moreover, the loss of benign aggregates in deeper sections is considered a prominent indicator of a benign process. ${ }^{4}$

To conclude, BMB is required for staging and evaluation of lymphomas and is performed even when the likelihood

\section{(C) 2021. MedIntel Services Pvt Ltd}

This is an open access article published by Thieme under the terms of the Creative Commons Attribution-NonDerivative-NonCommercial-License, permitting copying and reproduction so long as the original work is given appropriate credit. Contents may not be used for commercial purposes, or adapted, remixed, transformed or built upon. (https://creativecommons.org/licenses/by-nc-nd/4.0/).

Thieme Medical and Scientific Publishers Private Ltd A-12, Second Floor, Sector -2, NOIDA -201301, India
How to cite this article: Kalra S. K, Sancheti S, Somal P. K, et al. Morphology and Immunoprofiling of Benign Lymphoid Aggregates in Bone Marrow Biopsies of Lymphoma Patients South Asian J Cancer 2021;10(4):265-266.
Address for correspondence Dr. Sankalp Sancheti, Department Sangrur, Punjab, India (e-mail: sankalpsancheti123@rediff.com). 
Table 1 Morphological and immunohistochemical differences between benign and malignant lymphoid aggregates in bone marrow biopsies

\begin{tabular}{|l|l|l|l|}
\hline S. No. & Morphological characteristics & Benign lymphoid aggregates in BMB & $\begin{array}{l}\text { Malignant lymphoid aggregates in } \\
\text { BMB }\end{array}$ \\
\hline 1. & Location & Interstitial, nonparatrabecular & Usually paratrabecular \\
\hline 2. & Size & Small size $(<600 \mu \mathrm{m})$ & Larger aggregates \\
\hline 3. & Borders & Distinct borders & Infiltrative edges \\
\hline 4. & Cytological atypia & No & Yes \\
\hline 5. & $\begin{array}{l}\text { B and T cell number and pattern } \\
\text { (on IHC) }\end{array}$ & $\begin{array}{l}\text { Predominance of T cells or a mixture of B } \\
\text { and T cells or a core of T cells surrounded } \\
\text { by B cells }\end{array}$ & $\begin{array}{l}\text { Predominance of B cells or a core of B } \\
\text { cells surrounded by T cells (except for } \\
\text { germinal center formation) }\end{array}$ \\
\hline
\end{tabular}

Abbreviations: BMB, bone marrow biopsy; IHC, immunohistochemistry.

of involvement is low, as it may portend an inferior clinical outcome and impact therapy selection. The presence of BLA should therefore be considered whenever examining the bone marrow biopsies. A good knowledge of morphology and immunohistochemistry along with the clinical details, flow cytometry findings, and peripheral blood picture are of utmost importance to guide the pathologist in this regard.

\section{References}

1 Johnston A, Brynes RK, Naemi K, et al. Differentiating benign from malignant bone marrow B-cell lymphoid aggregates: a statistical analysis of distinguishing features. Arch Pathol Lab Med 2015;139(2):233-240

2 Vassilakopoulos TP, Angelopoulou MK, Constantinou N, et al. Development and validation of a clinical prediction rule for bone marrow involvement in patients with Hodgkin lymphoma. Blood 2005;105(5):1875-1880

3 Foucar K, Viswanatha DS, Wilson CS, Non-neoplastic lymphoid and plasma cell disorders. In: King DW, ed. Non-Neoplastic Disorders of Bone Marrow. Washington, DC: American Registry of Pathology; 2008 249-282. AFIP Atlas of Nontumor Pathology; 1st series

4 Salisbury JR, Deverell MH, Cookson MJ. Three-dimensional reconstruction of benign lymphoid aggregates in bone marrow trephines. J Pathol 1996;178(4):447-450 